\title{
THE EVALUATION OF WATER USE EFFICIENCY BASED ON ECONOMIC PERSPECTIVE IN CHINA FOR THE PERIOD 1999-2011
}

\author{
Lu GAO ${ }^{1}$, Wenli XU² ${ }^{2}$, Sayaka YOSHIKAWA ${ }^{3}$, Naoya $\mathrm{ABE}^{4}$, Shinjiro KANAE \\ ${ }^{1}$ Member of JSCE, D1, Dept. of Civil Engineering, Tokyo Institute of Technology (2-12-1 O-okayama, Meguro-ku, \\ Tokyo 152-8552, Japan) \\ ${ }^{2}$ Nonmember of JSCE, D1, Economics and management school, Wuhan University (Luojia Hill, Wuhan University, \\ Wuhan, China) \\ 3 Member of JSCE, Ph.D., Postdoctoral Fellow, Dept. of Civil Engineering, Tokyo Institute of Technology (2-12-1 \\ O-okayama, Meguro-ku, Tokyo 152-8552, Japan) \\ ${ }^{4}$ Nonmember of JSCE, Ph.D., Associate Professor, Dept. of International Development Engineering, Tokyo Institute \\ of Technology (2-12-1 O-okayama, Meguro-ku, Tokyo 152-8552, Japan) \\ 5 Member of JSCE, Dr. of Eng., Professor, Dept. of Civil Engineering, Tokyo Institute of Technology (2-12-1 \\ O-okayama, Meguro-ku, Tokyo 152-8552, Japan)
}

\begin{abstract}
Water shortage has been becoming one of the most crucial issues in China, because of the rapidly increasing water demand for economic development. One way of alleviating water scarcity is to increase the efficiency of water use without developing additional water supplies. Therefore it is essential to develop a holistic policy tool which can help the policy-makers to decide the usage of water wisely. The fundamental work is to explicitly quantify the agricultural water use efficiency in target areas. In this study, the agriculture water use efficiency is measured by the Data Envelopment Analysis (DEA) method, and recommendations of sustainable water use are provided.
\end{abstract}

Key Words: Water use efficiency, DEA, DEA window analysis

\section{INTRODUCTION}

Water scarcity has been becoming a severe problem in China because of the rapid growth of population and economic development. In 2011, the total annually available water resources in China are 2,813 billion $\mathrm{m}^{3}$. With a population of 1.4 billion, the available water usage per capita is $2,083 \mathrm{~m}^{3}$, only one-third of the world's average water use. However, the target for the current Five-Year Guideline of China is to achieve around $7.5 \%$ annual growth of GDP. At present, $61.3 \%$ of water is used for agriculture, which accounts for only $8.9 \%$ of GDP, and China's water use efficiency is lower than that of developed countries. Because industrial output has increasingly become much more profitable than agricultural output and the government wants to reach the goal of economic growth, more water resources are being transferred to industry. Consequently, irrigation water shortage is becoming an increasingly serious problem which will affect the agricultural production.
A major current focus in alleviating irrigation water scarcity is by increasing the efficiency of water use without development of additional water supplies ${ }^{1)}$. Initially, productivity of a production unit was used as irrigation efficiency, such as the amount of water to be applied per irrigated area ${ }^{7}$, crop yield per unit of applied water ${ }^{8)}$. The concept of productivity is similar to the efficiency, but not equal. Lovell (1993) defines the efficiency of a production unit in terms of a comparison between observed and optimal values of its output and inputs. In addition, we should also consider the allocation of resource when we want to both increase the economic level and save water resource. For instance, if we used as same volume water as last year and the agricultural production was increased, but we used more fertilizer than last year, we can't say the efficiency is improved. Consequently, we should choose the methodology which has an economic rather than an engineering meaning.

From an economic perspective, two major 
approaches to measure efficiency have been evolved, namely parametric and no-parametric approaches. The former one is based on the stochastic frontier production function method and the latter one is based on the DEA methodology, both of which are among the most popular techniques.

We adopt DEA to analyze water use efficiency, because there are following advantages. First, it doesn't need to explicitly specify a mathematical form for the frontier technology or the distribution of the inefficiency term. Second, the approach allows the comparison of one production method with the others in terms of a performance index. Moreover, it provides a straightforward approach to calculating the efficiency gap that separates each producer's behavior from best productive practices.

This approach has been widely used in management science and economics. Researchers in the field of water resource management also utilizes $\mathrm{DEA}^{2), 3)}$, for the static or comparatively static analysis. However, as the results obtained from DEA method are relative efficiency, the efficiency change of the producers in different years cannot be expressed. Therefore, a dynamic DEA method named DEA Window Analysis is used in this study to evaluate the efficiency change over time.

The primary objective of this study is to estimate the change of agricultural water use efficiency for the period 1999-2011 when the rate of economic growth is high. 31 provinces in China are selected as the target areas.

\section{METHODOLOGY}

Based on the pioneering work initiated by Farrell (1957), DEA was described by Charnes et al. (1978) to estimate an empirical production technology frontier for the first time. Later this method was developed by the Banker (1984) and applied in various fields. Researchers in the field of water resource management also utilizes DEA, e.g. Speelman et al. (2008) used small-scale irrigation schemes in North-West Province in South Africa to analyze the water use efficiency with DEA. However, in most of those previous researches, the Decision Making Unit (DMU) was evaluated within each period of time. Some researchers use a Malmquist index in the DEA framework for measuring efficiency change over time, such as M.K. Ali and Klein (2014), they measured the water use efficiency and productivity in Southern Alberta for the period 2008-2012 to establish benchmarks of water use. But based on the features of water resource, we should know the intertemporal efficiency change to comprehend the actual water use efficiency.

For these reasons, the input-oriented model of the DEA window analysis, which is useful to detect performance trends of a unit over time, was chosen to estimate the efficiency in this study.

\section{(1) CCR model}

DEA is used to measure the relative efficiency of homogenous units called DMU5). For the $k$ th DMU, $y_{r k}(r=1, \ldots, s)$ represent the level of the $r$ th output, and $x_{i k}(i=1, \ldots, m)$ represents the level of the $i$ th input. We formed the virtual input and output by weights $\left(v_{i}\right)$ and $\left(u_{r}\right)$ respectively, the efficiency of DMU $\mathrm{k}\left(\theta_{k}\right)$ is calculated by Eq. (1):

$$
\begin{aligned}
\theta_{k} & =\frac{\text { weighted sum of outputs }}{\text { weighted sum of inputs }} \\
& =\frac{u_{1} y_{1 k}+u_{2} y_{2 k}+\cdots+u_{s} y_{s k}}{v_{1} x_{1 k}+v_{2} x_{2 k}+\cdots+v_{m} x_{m k}}
\end{aligned}
$$

We solve the following linear programming problem to obtain values for the weights $\left(v_{i}\right.$ and $\left.u_{r}\right)$ as variables.

$$
\begin{array}{ll}
\operatorname{Max} & u_{1} y_{1 k}+u_{2} y_{2 k}+\cdots+u_{s} y_{s k} \\
\text { Subject to } & v_{1} x_{1 k}+v_{2} x_{2 k}+\cdots+v_{m} x_{m k}=1 \\
& u_{1} y_{1 k}+\cdots+u_{s} y_{s k}<v_{1} x_{1 k}+\cdots v_{m} v_{m k} \\
& v_{1 k}, \cdots, v_{m k} \geq 0 \quad u_{1 k}, \cdots, u_{s k} \geq 0
\end{array}
$$

Finally, before solving, the linear program is converted to its dual for computational efficiency reasons:

Min

$$
\theta_{k}
$$

$$
\begin{array}{cc}
\text { s.t. } \theta_{k} x_{i k}-\sum_{j=1}^{n} \lambda_{j} x_{i j} \geq 0, & i=1, \ldots, m, \\
\sum_{j=1}^{n} \lambda_{j} y_{r j} \geq y_{r k}, & r=1, \ldots, s, \\
\lambda_{j} \geq 0 &
\end{array}
$$

This is one of the most basic DEA models, CCR model which was proposed by Charnes, Cooper and Rhodes in 1978. This model is built on the assumption of constant returns to scales of activities. Efficiency $\left(\theta_{k}\right)$ value is never greater than 1 . If the efficiency is 1 , it means that the DMU is efficient; otherwise, it is inefficient.

With the addition of slack variables, the dual problem becomes:

Min $\theta_{k}$

$$
\begin{array}{ll}
\text { s.t. } & \theta_{k} x_{i k}-\sum_{j=1}^{n} \lambda_{j} x_{i j}=\sum_{i=1}^{m} s_{i}^{-}, i=1, \ldots, m, \\
& \sum_{j=1}^{n} \lambda_{j} y_{r j}=y_{r k}+\sum_{r}^{s} s_{r}^{+}, r=1, \ldots, s,
\end{array}
$$




$$
\lambda_{j} \geq 0
$$

The slack variables can be interpreted as the output shortfall and the input overconsumption compared to the efficiency frontier.

\section{(2) BCC model}

The CCR model is designed with the assumption of constant returns to scale. This is means that there is no assumption that any positive or negative economies of scales exist. It is assumed that a small scale irrigation should be able to be as efficient as a large one, that is, constant returns to scale. In order to address this, Banker, Charnes, and Cooper developed the BCC model which is built on the assumption of variable returns to scales of activities.

The BCC model is closely related to the CCR model as evident in the dual of the BCC model:

Min

s.t.

$$
\begin{aligned}
& \theta_{k} x_{i k}-\sum_{j=1}^{n} \lambda_{j} x_{i j} \geq 0, \quad i=1, \ldots, m, \\
& \sum_{j=1}^{n} \lambda_{j} y_{r j} \geq y_{r k}, \quad r=1, \ldots, s, \\
& \lambda_{j} \geq 0, \sum_{j-1}^{n} \lambda_{j}=1 \quad j=1, \ldots, n,
\end{aligned}
$$$$
\theta_{k}
$$

The difference compared to the CCR model is the introduction of the convexity condition $\Sigma \lambda=1$. This additional constraint gives the frontiers piecewise linear and concave characteristics.

Table 1 DEA efficiencies and their explanations

\begin{tabular}{|c|c|c|}
\hline Concept & Explanation & Detail \\
\hline \hline PTE & $\begin{array}{c}\text { The conversion of } \\
\text { physical inputs into } \\
\text { outputs relative to the } \\
\text { best practice }\end{array}$ & $\begin{array}{c}\text { For the current technical } \\
\text { level, the inputs are } \\
\text { completely utilized. }\end{array}$ \\
\hline SE & $\begin{array}{c}\text { For a given level of } \\
\text { output, inputs are } \\
\text { chosen to minimize } \\
\text { the cost of production }\end{array}$ & $\begin{array}{c}\text { Indicates whether the } \\
\text { scale of production is } \\
\text { overlarge or insufficient }\end{array}$ \\
\hline TE & $\begin{array}{c}\text { The combination of } \\
\text { pure technical and } \\
\text { scale efficiency. }\end{array}$ & $\begin{array}{c}\text { Is technically efficient if it } \\
\text { is both pure technically } \\
\text { and scale efficient. }\end{array}$ \\
\hline
\end{tabular}

The DEA defines three different forms of efficiency: Technical Efficiency (TE), Pure Technical Efficiency (PTE), and Scale Efficiency (SE). Table 1 explains the three efficiencies.

Inappropriate operation and inadequate scale of the farm are two main reasons for the inefficiency of a DMU. CCR model includes both PTE and SE while BCC model measures only PTE of DMU. Based on BCC and CCR scores, SE was defined as follows.

$$
S E=\frac{\mathrm{TE}(\mathrm{CCR} \text { scores })}{\mathrm{PTE}(\mathrm{BCC} \text { scores })}
$$

\section{(3) DEA window analysis}

A DEA window analysis works based on the principle of moving averages and is useful to detect efficiency trends of DMUs over time ${ }^{6}$. Herein the total number of DMUs is set as $\mathrm{N}$ and the total time is set as T. At each time, each DMU has common $r$ input items and $\mathrm{s}$ output items. The $n$th $(n=1, \ldots, N)$ observation in the $t$ th $(t=1, \ldots, T)$ period, referred as $D M U_{t}^{n}$, has an r-dimensional input vector $X_{t}^{n}=\left(x_{t}^{1 n} \cdots x_{t}^{r n}\right)$ and an s-dimensional output vector $Y_{t}^{n}=\left(y_{t}^{1 n} \cdots y_{t}^{s n}\right)$. If the window starts at time $\mathrm{k}(1 \leq k \leq T)$ with width w $(1 \leq w \leq T-k)$, then the vectors of inputs and outputs are represented as follows:

$$
\begin{gathered}
X_{k w}=\left(x_{k}^{1}, x_{k}^{2} \cdots x_{k}^{N}, \cdots, x_{k+w}^{1}, x_{k+w}^{2}, \cdots, x_{k+w}^{N}\right), \\
Y_{k w}=\left(y_{k}^{1}, y_{k}^{2}, \cdots, y_{k}^{N}, \cdots, y_{k+w}^{1}, y_{k+w}^{2}, \cdots, y_{k+w}^{N}\right) .
\end{gathered}
$$

By substituting inputs and outputs into the BCC and CCR models we can obtain the PTE and TE of the $D M U_{t}^{n}$ respectively. Because the PTE and TE value of each DMU change with time, so they can indicate the efficiency variation over time as well.

\section{(3) Input and output data}

For the purpose of evaluating agricultural water use efficiency for the period 1999-2011, the major sources of data were obtained from NBS Database, China Statistical Yearbook, and China Water Resources Bulletin. Because of the dominance of traditional agriculture in China, the agricultural production mainly depends on two factors, the input labor and natural resources.

Table 2 Descriptive Statistics of inputs and outputs.

\begin{tabular}{|l|c|c|c|c|}
\hline Statistics item & Max & Min & Mean & SD \\
\hline \hline Employment & 3558.55 & 33.38 & 971.51 & 759.94 \\
\hline Water & 1664.9 & 9.97 & 122.57 & 122.82 \\
\hline $\begin{array}{l}\text { Agricultural } \\
\text { gross product }\end{array}$ & 2255.03 & 13.3 & 469.02 & 420.96 \\
\hline
\end{tabular}

Additionally, considering data availability and what has been used in previous literature, the inputs are aggregated into two categories: the equivalent number of full time employees (unit: 10,000 persons, the number of employed persons in agricultural production), and the volume of agricultural water taken from surface and ground water resources (unit: 100 million $\mathrm{m}^{3}$, water served as most important natural resource). The output is 
the gross value of agricultural product (unit: 100 million Yuan).This index comprehensively reflects the value of agricultural products. Table 2 presents descriptive statistics of the variables.

\section{RESULTS AND DISCUSSION}

\section{(1) Water use efficiency}

The DEA window analysis efficiency scores are computed by employing the input-oriented model since it is assumed that the agricultural entities focuse on cost control have the possibility to adjust input usage, i.e., water usage.

Table 3 Agricultural water use efficiency average: a window DEA approach

\begin{tabular}{|c|c|c|c|}
\hline DMU & TE & PTE & SE \\
\hline \hline Beijing & 0.841 & 0.97 & 0.868 \\
\hline Tianjin & 0.79 & 0.923 & 0.854 \\
\hline Hebei & 0.79 & 0.795 & 0.994 \\
\hline Shanxi & 0.627 & 0.656 & 0.953 \\
\hline Inner & 0.658 & 0.669 & 0.984 \\
\hline Mongolia & 0.769 & 0.779 & 0.987 \\
\hline Liaoning & 0.849 & 0.86 & 0.987 \\
\hline Jilin & 0.705 & 0.715 & 0.987 \\
\hline Heilongjiang & 0.822 & 0.915 & 0.898 \\
\hline Shanghai & 0.821 & 0.839 & 0.98 \\
\hline Jiangsu & 0.772 & 0.781 & 0.988 \\
\hline Zhejiang & 0.636 & 0.642 & 0.991 \\
\hline Anhui & 0.711 & 0.72 & 0.988 \\
\hline Fujian & 0.593 & 0.6 & 0.989 \\
\hline Jiangxi & 0.857 & 0.861 & 0.995 \\
\hline Shandong & 0.76 & 0.808 & 0.945 \\
\hline Henan & 0.738 & 0.745 & 0.989 \\
\hline Hubei & 0.633 & 0.637 & 0.993 \\
\hline Hunan & 0.672 & 0.68 & 0.989 \\
\hline Guangdong & 0.568 & 0.571 & 0.993 \\
\hline Guangxi & 0.748 & 0.776 & 0.964 \\
\hline Hainan & 0.87 & 0.897 & 0.969 \\
\hline Chongqing & 0.711 & 0.729 & 0.977 \\
\hline Sichuan & 0.716 & 0.729 & 0.982 \\
\hline Guizhou & 0.56 & 0.573 & 0.977 \\
\hline Yunnan & 0.564 & 0.569 & 0.99 \\
\hline Tibet & 0.462 & 0.696 & 0.665 \\
\hline Shaanxi & 0.685 & 0.695 & 0.985 \\
\hline Gansu & 0.551 & 0.561 & 0.981 \\
\hline Qinghai & 0.461 & 0.673 & 0.685 \\
\hline Ningxia & 0.495 & 0.534 & 0.925 \\
\hline Xinjiang & 0.711 \\
\hline
\end{tabular}

To estimate the dynamic agricultural water use efficiency scores during 1999-2011 in China, the software EMS (Efficiency Measurement System) was used. We firstly use CCR model and DEA window analysis model to obtain the TE scores of different regions in China. Then in order to understand the reasons of inefficient TE, the PTE and SE was evaluated. The BCC model and DEA window analysis model were used to estimate the PTE score. And the SE is calculated by Eq. (10). We present the average water use efficiency results of 31 provinces of China in Table 3. Following results can be found from Table 3. (i) 11 out of 31 regions possess average TE score above $0.75,12$ out of 31 regions possess average TE score around 0.60 - 0.75 and 8 regions are below 0.60. (ii) With respect to PTE, Beijing is the best while Gansu is the worst. (iii) The SE differs greatly from TE and PTE. It is worth noting that most of the provinces' SE averages are relatively high compared with the PTE value, indicating that the scale size is appropriate. The SE average reveals that Hebei is the best performer and Qinghai is the worst.

In order to find out the relationship between water resource endowment and water use TE, 31 provinces are divided into three groups according to the rank of annual average amount of water resource. Detailed information of the regions is shown in Table 4. Furthermore, we illustrate the average TE of 31 provinces of China in Fig.1.

Table 4 Group concept and their explanations

\begin{tabular}{|c|c|}
\hline Areas & Regions \\
\hline $\begin{array}{l}\text { Rich in water } \\
\text { resources area } \\
\quad(\text { Top } 7)\end{array}$ & $\begin{array}{l}\text { R1.Tibet, R2.Sichuan, R3.Yunnan, } \\
\text { R4.Guangxi, R5.Guangdong, } \\
\text { R6.Hunan, R7.Jiangxi }\end{array}$ \\
\hline $\begin{array}{l}\text { Lack of water } \\
\text { resources area } \\
(\text { Top 8-22) }\end{array}$ & $\begin{array}{l}\text { L1.Cuizhou, L2.Fujian, L3.Hubei, } \\
\text { L4.Zhejiang, L5.Xinjiang, L6.Anhui, } \\
\text { L7.Shaanxi, L8.Hilongjiang, } \\
\text { L9.Qinghai, L10.Chongqing, } \\
\text { L11.Hainan, L12.Henan, } \\
\text { L13.Shandong, L14.Jiangsu, L15.Inner } \\
\text { Mongolia }\end{array}$ \\
\hline $\begin{array}{l}\text { Water resources } \\
\text { shortage area(Top } \\
\text { 23-31) }\end{array}$ & $\begin{array}{l}\text { S1.Jinlin, S2.Liaoning, S3.Gansu, } \\
\text { S4.Hebei, S5.Shanxi, S6.Shanghai, } \\
\text { S7.Ningxia, S8.Beijing, S9.Tianjin }\end{array}$ \\
\hline
\end{tabular}

The Figure 1 shows the following: (i) in abundant water resources area: 3 provinces (Hunan, Guangdong, and Sichuan) have average TE scores between 0.6-0.75. And 4 provinces (Tibet, Yunnan, Guangxi and Jiangxi) are below 0.6, which is considered as low efficiency. (ii) In insufficient water resources area: 5 provinces (Henan, Zhejiang, Jiangsu, Shandong and Chongqing) are highly efficient with average TE scores above $0.75,8$ 
provinces (Anhui, Inner Mongolia, Shaanxi, Heilongjiang, Fujian, Xinjiang, Hubei and Hainan) have average TE scores around 0.6-0.75 and 2 provinces (Qinghai and Guizhou) are inefficient with average TE scores below 0.6. (iii) In water resources shortage area: 6 provinces (Liaoning, Tianjin, Hebei, Shanghai, Beijing and Jilin) are highly efficient with average TE scores above 0.75 and 3 provinces (Ningxia, Gansu and Shanxi) are below 0.75 , which is consider as relatively low efficiency.

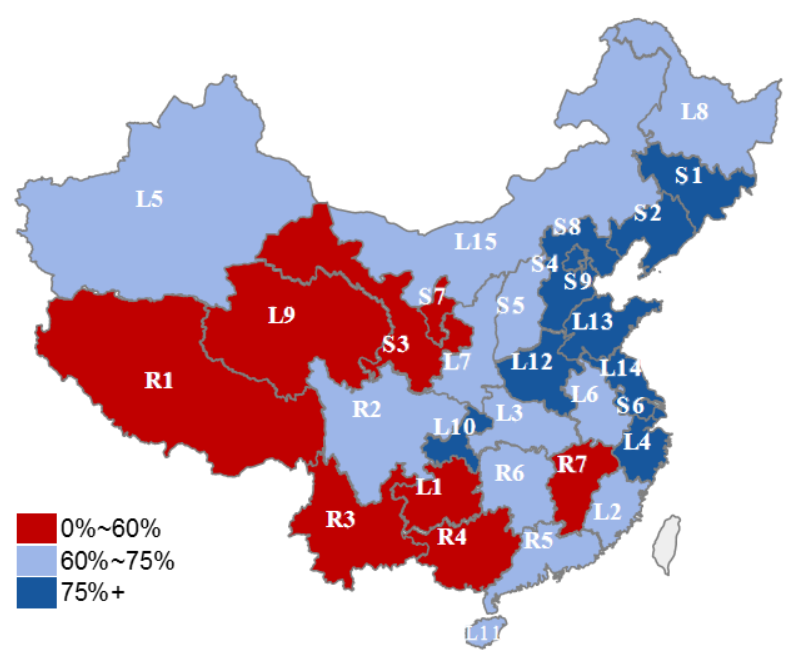

Fig.1 China Agriculture water use efficiency performance 1999-2011

We also divided 31 provinces into three major areas based on GDP per capital ${ }^{9)}$ in order to identify the relationship between the economic grow and agricultural water use efficiency:

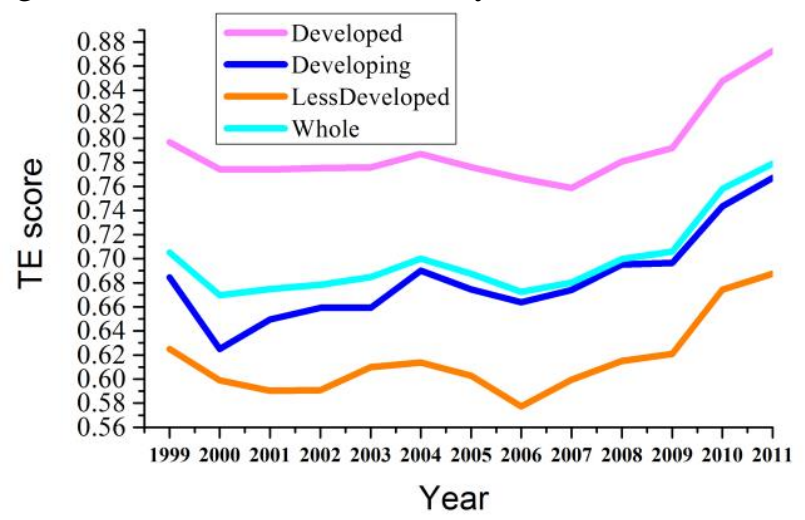

Fig.2 Average TE score of China and its three areas

1) The developed area, which has experienced the rapidest economic growth in China in the past 30 years and its average GDP is around half of Chines Total GDP. (Beijing, Tianjin, Hebei, Liaoning, Shanghai, Jiangsu, Zhejiang, Fujian, Shandong, Guangdong, Hainan), 2) the developing area (Inner Mongolia, Anhui, Jiangxi, Hunan, Guangxi, Heilongiiang, Henan, Hubei, Jilin, Shanxi), and 3) the less-developed area (other provinces).
The result of average TE scores of three area and all of the provinces for each year from 1999 to 2011 are show in Fig 2.This figure indicates the following results: (i) every year the developed area exhibits the highest average TE score. The developing area has a better TE score than the less-developing area, but both of these are below the average TE score at the whole provinces level. (ii) All of the three areas have similar increase and decrease trends during the period of 1999 to 2011.

\section{(2) Slack of input (water withdrawal)}

The redundant amounts of inputs or shortfalls amounts of outputs can be calculated as the gap between their actual and target results, which is called slack. In other words, the value of slack expresses how much water or labor we can save when the DMU reaches the DEA efficient without reduce agricultural gross product.

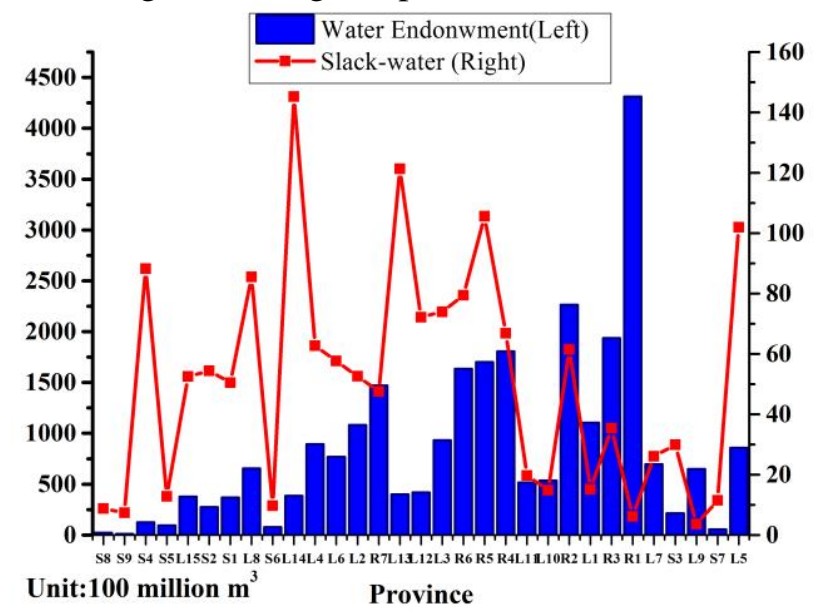

Fig.3 Average input's slack and water endowment

Because in this study we just want to focus on the water use, the Fig. 3 just shows the average slack value of the water withdrawal. In order to understand the natural situation, the water endowment is also summarized in Fig.3. It illustrates that the top ten water saving potentiality provinces are 1).Jiangsu (145.2), 2).Shandong (121.3), 3).Guangdong (105.6), 4).Xinjiang (102.0), 5).Hebei (88.2), 6).Heilongjiang (85.5), 7).Hunan (79.4), 8).Hubei (74.0), 9).Henan (72.2), 10).Guangxi (66.8). And the top ten water endowment provinces are 1).Tibet (4313.1), 2).Sichuan (2263.3), 3).Yunnan (1935.5), 4).Guangxi (1805.9), 5).Guangdong (1700.9), 6).Hunan (1635.3), 7).Jiangxi (1469.8), 8).Guizhou (1102.7), 9).Fujian (1083.1), 10).Hubei (930.6).

\section{(2) Discussion of efficiency}

Even though over $80 \%$ of the water resources concentrated locate in the southeastern part of China where the arable area is only $35 \%$ of the country's 
total arable area, which is 95 million hectares, the agricultural water use efficiency in the western and southern regions where are rich in water resources can be considered as low water use efficiency areas. It means that agricultural water use efficiency trend to be lower in the regions where the water resource is sufficient.

In general, the TE score and economic growth has positive correlation. The less-developing area has the lowest TE score compared to the developing and developed areas. It means the developing level of the area also affects the water use efficiency.

For the purpose of exporting the primary sources of efficiency change, TE score was decomposed into PTE and SE. For a specific region, if the SE is greater than PTE, improvements should be carried out in management practices, such as adjusting irrigation water and labor. If the SE is smaller than PTE, the scale of production should be adjusted. In Table 3, the influence of PTE on TE is greater than that of SE for most of the provinces. Thus the management practices should be improved, such as adjusting the ratio and the amount of irrigation water and labor, in order to achieve the efficient frontier.

Because the TE is effected by PTE more than SE, we estimate the slack in each region to evaluate the adjust amount of inputs. In order to evaluate the water saving capacity, the slack is estimated. From the results, even though the water endowments in Jiangsu, Shandong, Xinjiang, Hebei, Heilongjiang, Henan are less than other provinces, the water saving capacity are larger than most of the the provinces. It indicates that the water transfer policy should not only consider the water endowment, but also think about the water saving capacity.

\section{CONCLUSION AND SUGGESTIONS}

This paper applies DEA window analysis to measure the dynamic agricultural water use efficiency of 31 provinces in China during 1999-2011, a period of rapid economic development and water resources consumption. To deal with panel data, this paper employs DEA window analysis to evaluate the efficiency scores.

In terms of the water use efficiency, several major findings were obtained. First, agricultural water use efficiency trends to be lower in the regions where the water resource is sufficient. Moreover, the developed area has higher TE score than the developing area and the efficiency of the less-developed area is the worst. It may be thought that the economic development mode of China causes the relatively low TE. In addition, the influence of PTE on TE is greater than that of SE in most provinces. Lastly, the water saving capacity is not based on the water endowment. Therefore, we give some suggestions to improve China agricultural water use efficiency. (1) The public awareness of water-saving should be enhanced in water abundant area. (2) Increasing the agricultural investment in the developing area and the less-developed area. (3) Improve the water management in most provinces, except Beijing, Tianjin, Shanghai and Tibet. Besides, in those provinces, the scale of production should be adjusted. (4) If a water transfer project is conducted, such as South-North water transfer project, not only local water endowment but also the water saving capacity should be considered in order to eliminate the impact on the agricultural production.

Above all, the increasing water resource pressure worldwide has become a serious threat to human survival and development. To deal with the challenges, one of the most effective strategies is a persistent efficiency improvement.

ACKNOWLEDGMENT: This research was supported by CREST of the Japan Science and Technology Agency, and JSPS Grants-in-Aid for Scientific Research (ID: 23226012).

\section{REFERENCES}

1) Seckler, D., Molden, D., and Sakthivadivel, R.: The concept of efficiency in water resources management and policy, Water Productivity in Agriculture: Limits and Opportunities for Improvement, Kijne, J. W., Barker, R., and Molde, D. J. eds., IWMI, Sri Lanka, pp.37-51, 2003.

2) Speelman et al.: A measure for the efficiency of water use and its determinants, a case study of small-scale irrigation schemes in North-West Province, South Africa, Agricultural Systems, Vol.98, pp.31-39, 2008.

3) Ali, M. K., and Klein, K. K.: Water use efficiency and Productivity of the Irrigation Districts in Southern Alberta Water Resour. Manage., Vol.28, pp.2751-2766, 2014.

4) Lovell C.A.K., Production Frontiers and Productive Efficiency, Oxford University Press, UK, 1993.

5) Cooper W. W., Seiford, L., Tone, K.,: Data Envelopment Analysis: a comprehensive text with models, applications, references and DEA-Solver software (2nd ed.), Springer, New York, pp.326-327, 2006.

6) Yang, H., and Chang, C: Using DEA window analysis to mewasure efficiencies of Taiwan's integrated telecommunication firms, Telecommunications Policy, Vol.33, pp.98-108, 2009.

7) Deng, X., Shan, L., Zhang, H., and Turner, N. C.: Improving agricultural water use efficiency in arid and semiarid areas of China, Agric. Water Manage., Vol.80, pp. 23-40, 2006.

8) Balkhair et al., G.: Treated wastewater use and its effect on water conservation, vegetative yield, yield components and water use efficiency of some vegetable crops grown under two different irrigation systems in Western Region, Saudi Arabia, 1st Annual International Interdisciplinary Conference, AIIC 2013, Vol.4,pp.395-402, 2013.

9) Ke, W., Shiwei, Y., Wei, Z.: China's regional energy and environmental efficieny: A DEA window analysis based dynamic evaluation, Mathematical and computer modeling, Vol.58, pp.1117-1127, 2013.

(Received September 30, 2014) 